\title{
Inhibition of PA endonuclease activity of influenza virus RNA polymerase by Kampo medicines
}

\author{
Riku Shirayama ${ }^{1}$, Masaki Shoji ${ }^{1}$, Nongluk Sriwilaijaroen ${ }^{2,3}$, Hiroaki Hiramatsu ${ }^{3}$, Yasuo Suzuki ${ }^{3}$, \\ Takashi Kuzuhara, ${ }^{1, *}$ \\ ${ }^{1}$ Laboratory of Biochemistry, Faculty of Pharmaceutical Sciences, Tokushima Bunri University, Yamashiro-cho, Tokushima, Japan; \\ ${ }^{2}$ Faculty of Medicine, Thammasat University (Rangsit Campus), Pathumthani, Thailand; \\ ${ }^{3}$ College of Life and Health Sciences, Chubu University, Aichi, Japan.
}

\begin{abstract}
Summary To find a novel influenza inhibitor targeting the endonuclease activity of influenza A virus polymerase acidic protein (PA), which is essential for the acquisition of primers for viral mRNA transcription, seven Kampo extracts were tested in vitro for their ability to inhibit endonuclease activity of the recombinant PA protein that was expressed and purified from Escherichia coli. The Kampo medicines Kakkonto, Shosaikoto, Saikokeishito, Keishito, Maobushisaishinto, and Maoto, but not Chikujountanto, inhibited PA endonuclease activity in a dose-dependent manner. Our results indicate that Kampo medicines are good sources providing a structural lead for optimization of an influenza endonuclease inhibitor.
\end{abstract}

Keywords: Influenza virus, RNA polymerase, endonuclease, Kampo medicine

\section{Introduction}

By far, the worst influenza pandemic to date was the 1918 Spanish influenza A (H1N1) virus, which caused 50 million deaths worldwide $(1,2)$. Currently, the H3N2 Hong Kong/68 and H1N1 swine/09 pandemic variants cause severe illnesses in 3-5 million people and 250-500 thousand deaths per year $(3,4)$. In addition to annual epidemics, non-human influenza $A$ viruses sporadically infect humans. These infections can cause a severe disease and are associated with a high death rate. Highly mutable influenza A viruses not only cause occasional pandemics with unpredictable pathogenesis and annual epidemics, but also may cause the annual seasonal vaccine to fail and the development of resistance to antivirals (accordingly, vaccine formulation should be reviewed annually (5)). Both currently circulating $\mathrm{H} 3 \mathrm{~N} 2$ and $\mathrm{H} 1 \mathrm{~N} 1$ viruses are highly resistant to adamantanes targeting the viral M2 ion channel $(6,7)$ and $1.8 \%$ of $\mathrm{H} 1 \mathrm{~N} 1$ viruses tested in

Released online in J-STAGE as advance publication February 22, 2016.

*Address correspondence to:

Dr. Takashi Kuzuhara, Laboratory of Biochemistry, Faculty of Pharmaceutical Sciences, Tokushima Bunri University, Yamashiro-cho, Tokushima 770-8514, Japan.

E-mail: kuzuhara@ph.bunri-u.ac.jp
2013-2014 were resistant to oseltamivir, which targets viral neuraminidase (8). These observations indicate the urgent need for novel antivirals targeting essential viral proteins at sites that are highly conserved among strains to effectively control influenza outbreaks and prevent the development of drug resistance.

Influenza A viruses have a segmented single-stranded RNA (-) genome, and transcription and replication of the viral genome is catalyzed by a heterotrimeric RNAdependent RNA polymerase consisting of polymerase basic protein 1 (PB1) and 2 (PB2) and polymerase acidic protein (PA) $(9,10)$. The $N$-terminal domain (residues 1-220) of the PA subunit harbors endonuclease activity by which capped host pre-mRNAs are cleaved and then used as primers for viral mRNA synthesis, which is essential for virus multiplication $(11,12)$. Unlike other polymerase parts with mutations that are associated with virulence and interspecies transmission, the PA $N$-terminal active site is highly conserved between humans and avian species (11). This suggests that the PA $\mathrm{N}$-terminal endonuclease is a promising therapeutic target for influenza. Our previous results showed that catechins, phenethyl phenyl phthalimide analogs, marchantins, and fullerene $\mathrm{C}_{60}$ analogs inhibit PA endonuclease activity (in the influenza A virus H1N1 strain) and possess antiviral activity against influenza viruses $\mathrm{A}$ (H1N1 and/or H3N2) and/or B strains (13-16), supporting the hypothesis that the PA endonuclease is a candidate for the development 
Table 1. Composition of Kampo medicines

\begin{tabular}{|c|c|c|c|c|c|c|c|}
\hline \multirow{2}{*}{ Composition } & \multicolumn{7}{|c|}{ Weight ratio } \\
\hline & Kakkonto & Keishito & Shosaikoto & Shosaikoto & Maoto & Maobushisaishinto & Chikujountanto \\
\hline$J^{\mathrm{a}}$ Pueraria Root & 4.0 & & - & - & - & - & - \\
\hline JP Jujube & 3.0 & 4.0 & 2.0 & 3.0 & - & - & - \\
\hline JP Ephedra Herb & 3.0 & - & - & - & 5.0 & 4.0 & - \\
\hline JP Glycyrrhiza & 2.0 & 2.0 & 2.0 & 2.0 & 1.5 & - & 1.0 \\
\hline JP Cinnamon Bark & 2.0 & 4.0 & 2.0 & - & 4.0 & - & - \\
\hline JP Peony Root & 2.0 & 4.0 & 2.0 & - & - & - & - \\
\hline JP Ginger & 2.0 & 1.5 & 1.0 & 1.0 & - & - & 1.0 \\
\hline JP Bupleurum Root & - & - & 5.0 & 7.0 & - & - & - \\
\hline JP Pinellia Tuber & - & - & 4.0 & 5.0 & - & - & - \\
\hline JP Scutellaria Root & - & - & 2.0 & 3.0 & - & - & - \\
\hline JP Ginseng & - & - & 2.0 & 3.0 & - & - & 1.0 \\
\hline JP Asiasarum Root & - & - & - & - & - & 3.0 & - \\
\hline JP Powdered Processed Aconite Root & - & - & - & - & - & 1.0 & - \\
\hline JP Apricot Kernel & - & - & - & - & 5.0 & - & - \\
\hline JP Pinellia Tuber & - & - & - & - & - & - & 5.0 \\
\hline JP Bupleurum Root & - & - & - & - & - & - & 3.0 \\
\hline JP Ophiopogon Tuber & - & - & - & - & - & - & 3.0 \\
\hline JP Poria Sclerotium & - & - & - & - & - & - & 3.0 \\
\hline JP Platycodon Root & - & - & - & - & - & - & 2.0 \\
\hline JP Immature Orange & - & - & - & - & - & - & 2.0 \\
\hline JP Cyperus Rhizome & - & - & - & - & - & - & 2.0 \\
\hline JP Citrus Unshiu Peel & - & - & - & - & - & - & 2.0 \\
\hline JP Coptis Rhizome & - & - & - & - & - & - & 1.0 \\
\hline Bamboo Culm. & - & - & - & - & - & - & 3.0 \\
\hline Total $(\mathrm{g})$ & 18.0 & 15.5 & 22.0 & 24.0 & 15.5 & 8.0 & 29.0 \\
\hline
\end{tabular}

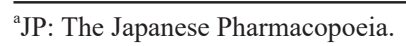

of the next generation of antivirals targeting a broad range of influenza A virus strains.

Kampo medicines are traditional Japanese herbal medicines that typically consist of several mixed herbs $(17,18)$. Recently, a Kampo medicine, maoto, was reported to have anti-influenza activity (18). Here, we provide evidence for anti-PA endonuclease activity in 6 of the 7 tested Kampo medicines, suggesting that Kampo medicines are potential sources of compounds for the development of new, selective PA endonuclease inhibitors.

\section{Materials and Methods}

\subsection{Kampo medicines}

Kampo medicines, including Kakkonto, Shosaikoto, Saikokeishito, Keishito, Maobushisaishinto, Maoto, and Chikujountanto, were obtained from Tsumura \& Co. (Tokyo, Japan). Based on the data sheets of Tsumura \& Co., the composition of Kampo medicines are summarized in Table 1. Kampo medicines were dissolved in the purified water at $10 \mathrm{mg} / \mathrm{mL}$ for in vitro assay.

\subsection{Bacterial expression and purification of influenza virus PA endonuclease}

The recombinant PA endonuclease was produced as described previously (13-16). Briefly, the influenza A/
PR/8/34 (H1N1) PA coding sequence corresponding to $\mathrm{N}$-terminal endonuclease residues 1-220 was amplified from the plasmid pBMSA-PA (Riken BioResource Center, Tsukuba, Japan) and was cloned into the bacterial expression plasmid pET28a(+) with the T7/ lac promoter plus $6 \mathrm{x}$ histidine (His)-tag sequence (Novagen, Madison, WI, USA). After the introduction of the plasmid into BL21-CodonPlus Escherichia coli cells (Stratagene, La Jolla, CA, USA), expression of the PA endonuclease protein-6xHis was induced by the addition of IPTG. The recombinant PA endonuclease6xHis was purified in a two-step process using $\mathrm{Ni}^{2+}$ affinity chromatography, followed by HiTrap ${ }^{\mathrm{TM}} \mathrm{Q}$ FF anion exchange chromatography with the AKTA ${ }^{\mathrm{TM}}$ Prime Plus System (GE Healthcare, Buckinghamshire, UK).

\subsection{PA endonuclease inhibition assay}

The recombinant PA endonuclease activity of the influenza A virus was determined following previously described methods (13-16), with modifications. The assay was performed in a $100 \mu \mathrm{L}$ reaction mixture containing $20 \mathrm{mM}$ Tris- $\mathrm{HCl}(\mathrm{pH} 7.3), 100 \mathrm{mM} \mathrm{NaCl}$, $2.5 \mathrm{mM} \mathrm{MnCl}_{2}, 10-50 \mu \mathrm{g} / \mathrm{mL}$ circular single-stranded DNA (M13mp18) as a substrate, and $5 \mu \mathrm{M}$ recombinant PA endonuclease. After $30 \mathrm{~min}$ of digestion at $37^{\circ} \mathrm{C}$, the digestion reaction was stopped by the addition of $20 \mathrm{mM}$ EGTA. The undigested M13mp18 substrate remaining in the reaction as well as a reaction without 
the recombinant PA endonuclease were analyzed by $0.7 \%$ agarose gel electrophoresis in Tris-borate-EDTA buffer and visualized by staining the gel with ethidium bromide. For the inhibition assay, each Kampo medicine at various concentrations was preincubated with the PA endonuclease in the reaction mixture at $37^{\circ} \mathrm{C}$ for 5 minutes, before adding the substrate to initiate the digestion reaction. The inhibitory effects of each Kampo medicine on PA endonuclease activity were determined on the basis of the ability the medicine to maintain the same intensity of the M13mp18 band as that of the reaction mixture without the $\mathrm{PA}$ endonuclease. The reaction that did not include the inhibitor was defined as the maximum diminution of the substrate band (i.e., full PA endonuclease activity).

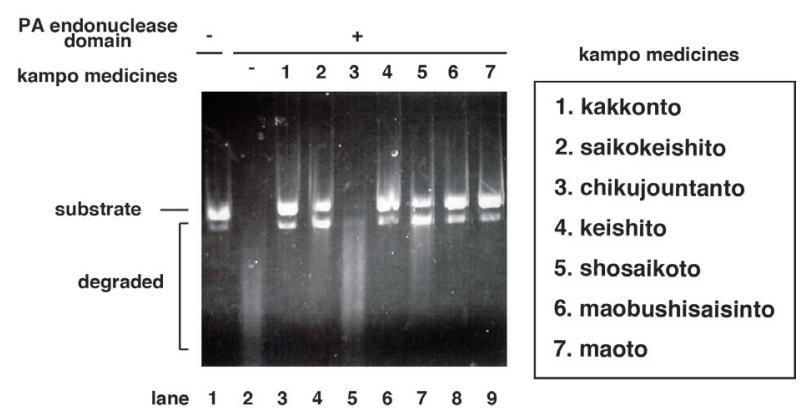

Figure 1. Inhibition of PA endonuclease activity by Kampo medicine extracts. The recombinant PA endonuclease (5 $\mu \mathrm{M}$ ) was pre-incubated with the solvent (water) control (each Kampo medicine was dissolved in water) (Lane 2) or different Kampo medicines $(1 \mathrm{mg} / \mathrm{ml})$ as indicated (Lanes 3-9) prior to starting the reaction by the addition of M13mp18 substrate $(50 \mu \mathrm{g} / \mathrm{mL})$. As a negative control, the reaction was performed in the absence of the endonuclease; thus, the substrate should remain intact in the reaction (Lane 1). The remaining substrate for each reaction after endonuclease digestion $(20 \mu \mathrm{L}$ from a total reaction volume of $100 \mu \mathrm{L}$ ) was analyzed by $0.7 \%$ agarose gel electrophoresis.

\section{Results and Discussion}

After transformation of the pET28a(+) plasmid, which carries the influenza PA cDNA coding region spanning the first $220 \mathrm{~N}$-terminal amino acid residues (responsible for endonuclease activity) from the pBMSA-PA plasmid by PCR-based cloning in BL21-CodonPlus E. coli cells, the recombinant PA endonuclease was induced and purified for the in vitro endonuclease assay. An assay of the cleavage of the phosphodiester bond within a polynucleotide chain by the recombinant PA endonuclease was performed at $\mathrm{pH} 7.3$ to mimic the nucleus of an infected cell, where the cap-snatching endonuclease is located (11), using M13mp18 circular single-stranded DNA as a substrate. In the absence of the endonuclease, the M13mp18 substrate remained intact after the reaction, as shown in Lane 1, Figure 1. In the presence of the endonuclease, the substrate was cleaved and thus reduced upon the endonuclease cleavage activity. The complete reduction of band intensities was observed (Lane 2, Figure 1), indicating that $5 \mu \mathrm{M}$ PA endonuclease can achieve complete cleavage of all of the $50 \mu \mathrm{g} / \mathrm{mL}$ substrate within $30 \mathrm{~min}$ under the assay conditions. The addition of $1 \mathrm{mg} / \mathrm{mL}$ Kakkonto, Shosaikoto, Saikokeishito, Keishito, Maobushisaishinto, or Maoto, but not Chikujountanto, significantly inhibited the digestion of the M13mp18 substrate.

To examine the dose-dependent effects of Kampo medicines on recombinant PA endonuclease activity, 5 $\mu \mathrm{M}$ endonuclease was pre-treated with serial 10 -fold dilutions of Kampo medicines in the reaction mixture before the addition of $10 \mu \mathrm{g} / \mathrm{mL}$ M13mp18. All Kampo medicines, except Chikujountanto, at $100 \mu \mathrm{g} / \mathrm{mL}$ could abolish recombinant PA endonuclease activity as evidenced by the lack of a change in substrate levels (Figure 2). Similar decreases in substrate band

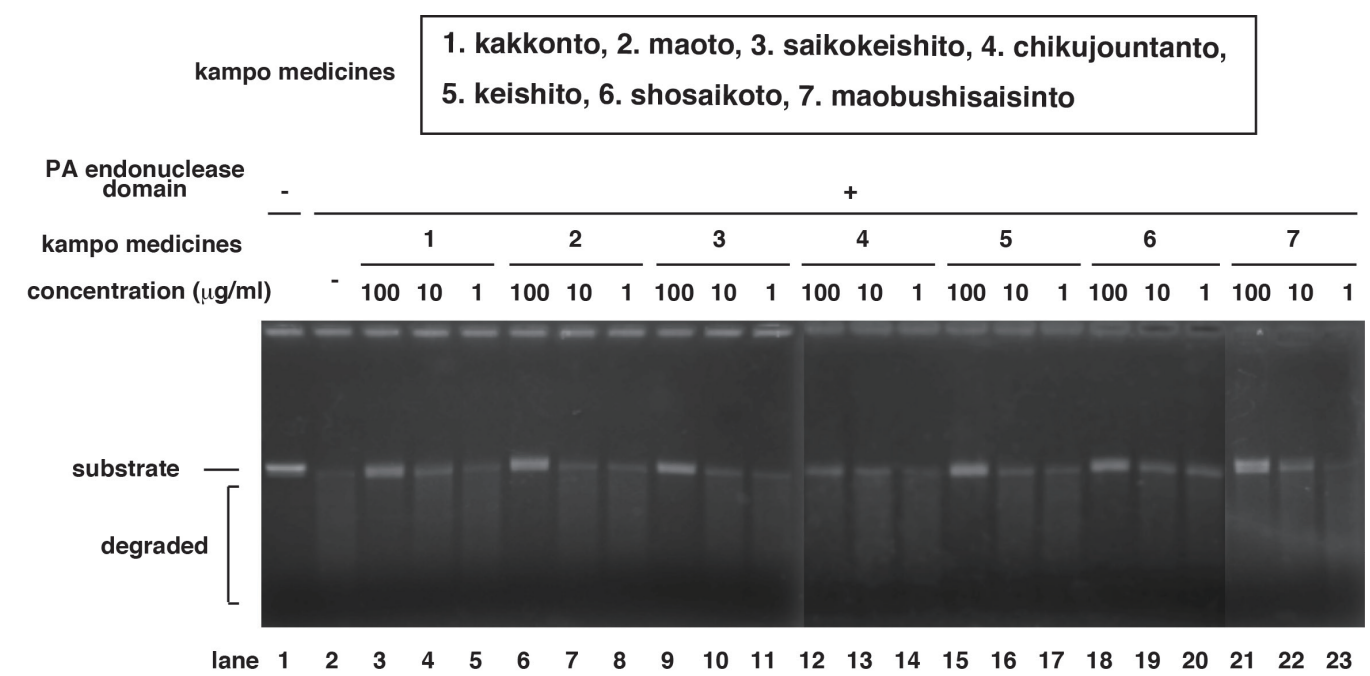

Figure 2. Dose-dependent inhibition of PA endonuclease by Kampo medicines. The activity of the recombinant PA endonuclease $(5 \mu \mathrm{M}$ ) was determined in the absence (Lane 2) or the presence of various concentrations (from 1 to $100 \mu \mathrm{g} / \mathrm{mL}$, as indicated) of different Kampo medicines as indicated (Lanes 3-23) using M13mp18 (10 $\mu \mathrm{g} / \mathrm{mL})$ as a substrate. A negative control without the endonuclease was evaluated in parallel (Lane 1). A $20-\mu \mathrm{L}$ volume of each reaction from a total reaction volume of $100 \mu \mathrm{L}$ was examined by $0.7 \%$ agarose gel electrophoresis. 
intensities were observed using 1 and $10 \mu \mathrm{g} / \mathrm{mL}$ Kampo medicines, but the band intensities remained slightly higher than that of the reaction without a Kampo medicine (Lane 2), indicating that 1 and $10 \mu \mathrm{g} / \mathrm{mL}$ Kampo medicines can slightly decrease endonuclease activity. These results confirmed that Chikujountanto does not demonstrate significant inhibitory activity against the endonuclease under these assay conditions and that the Kampo medicines Kakkonto, Shosaikoto, Saikokeishito, Keishito, Maobushisaishinto, and Maoto, at concentrations greater than $10 \mu \mathrm{g} / \mathrm{mL}$, significantly inhibit endonuclease activity.

The endonuclease activity of the $N$-terminus of PA, which has a highly conserved sequence and has an essential function for influenza virus transcription and multiplication, has been identified as a potential target for developing novel anti-influenza virus drug (19) with low susceptibility to viral resistance. We demonstrate here that several Kampo medicines including Kakkonto, Shosaikoto, Saikokeishito, Keishito, Maobushisaishinto, and Maoto are able to inhibit recombinant PA endonuclease activity, whereas Kampo medicine Chikujountanto at a highest tested concentration of $100 \mu \mathrm{g} / \mathrm{mL}$ is unable to inhibit the enzyme activity. Variation in composition between active Kampo medicines and the inactive Kampo medicine chikujountanto might account for the observed differences in endonuclease susceptibility (Table 1). Investigation of chemical compounds in Kampo medicine composition using three-dimensional HPLC analyses indicated that cinnamic acid is present in all tested Kampo medicines, except Chikujountanto. However, cinnamic acid at 2.5-20 $\mu \mathrm{M}$ does not appear to inhibit recombinant PA endonuclease activity (data not shown). Further studies are thus required to isolate and identify the active compounds of Kampo medicines that target the PA endonuclease.

In summary, we showed that the Kampo medicines Kakkonto, Shosaikoto, Saikokeishito, Keishito, Maobushisaishinto, and Maoto possess inhibitory activity against influenza viral PA endonuclease. They cleave the 5 ' cap of host pre-mRNAs for use as primers for the synthesis of viral mRNAs as templates for viral protein synthesis, which is critical for viral multiplication (20). These Kampo medicines are thus valuable materials for the future discovery and development of active anti-PA compounds for novel anti-influenza therapeutics.

\section{Acknowledgements}

The RNA polymerase PA plasmid pBMSA-PA of the influenza $\mathrm{A} / \mathrm{PR} / 8 / 34$ (H1N1) virus was provided by the DNA bank, Riken BioResource Center (Tsukuba, Japan; originally deposited by Susumu Nakada (21)). We thank Tsumura \& Co. (Tokyo, Japan) for providing Kampo medicines with the results of the 3D-HPLC analyses.
This work was supported by the National BioResources Project of the Ministry of Education, Culture, Sports, Science, and Technology of Japan and the Japan Society for the Promotion of Science (JSPS), Grants-inAid for Scientific Research (C) 25460574 (to T.K.).

\section{References}

1. Horimoto T, Kawaoka Y. Influenza: lessons from past pandemics, warnings from current incidents. Nat Rev Microbiol. 2005; 3:591-600.

2. Neumann G, Noda T, Kawaoka Y. Emergence and pandemic potential of swine-origin H1N1 influenza virus. Nature. 2009; 459:931-939.

3. Sriwilaijaroen N, Suzuki Y. Molecular basis of a pandemic of avian-type influenza virus. Methods Mol Biol. 2014; 1200:447-480.

4. WHO. Influenza (Seasonal). http://www.who.int/ mediacentre/factsheets/fs211/en/ (accessed September 20, 2015).

5. CDC. Key facts about seasonal flu vaccine. http://www. cdc.gov/flu/protect/keyfacts.htm (accessed September 20, 2015).

6. CDC. Antiviral drug resistance among influenza viruses. http://www.cdc.gov/flu/professionals/antivirals/antiviraldrug-resistance.htm (accessed September 20, 2015).

7. Hayden FG, de Jong MD. Emerging influenza antiviral resistance threats. J Infect Dis. 2011; 203:6-10.

8. CDC. Influenza Antiviral Drug Resistance. http://www. cdc.gov/flu/about/qa/antiviralresistance.htm (accessed September 20, 2015).

9. Kuzuhara T, Kise D, Yoshida H, Horita T, Murazaki Y, Nishimura A, Echigo N, Utsunomiya H, Tsuge H. Structural basis of the influenza A virus RNA polymerase PB2 RNA-binding domain containing the pathogenicitydeterminant lysine 627 residue. J Biol Chem. 2009; 284:6855-6860.

10. Sriwilaijaroen N, Suzuki Y. Molecular basis of the structure and function of $\mathrm{H} 1$ hemagglutinin of influenza virus. Proc Jpn Acad Ser B Phys Biol Sci. 2012; 88:226249.

11. Dias A, Bouvier D, Crépin T, McCarthy AA, Hart DJ, Baudin F, Cusack S, Ruigrok RW. The cap-snatching endonuclease of influenza virus polymerase resides in the PA subunit. Nature. 2009; 458:914-918.

12. Yuan P, Bartlam M, Lou Z, Chen S, Zhou J, He X, Lv Z, Ge R, Li X, Deng T, Fodor E, Rao Z, Liu Y. Crystal structure of an avian influenza polymerase PA(N) reveals an endonuclease active site. Nature. 2009; 458:909-913.

13. Iwai Y, Takahashi H, Hatakeyama D, Motoshima K, Ishikawa M, Sugita K, Hashimoto Y, Harada Y, Itamura S, Odagiri T, Tashiro M, Sei Y, Yamaguchi K, Kuzuhara T. Anti-influenza activity of phenethylphenylphthalimide analogs derived from thalidomide. Bioorg Med Chem. 2010; 18:5379-5390.

14. Iwai Y, Murakami K, Gomi Y, Hashimoto T, Asakawa Y, Okuno Y, Ishikawa T, Hatakeyama D, Echigo N, Kuzuhara T. Anti-influenza activity of marchantins, macrocyclic bisbibenzyls contained in liverworts. PLoS One 2011; 6:e19825.

15. Kuzuhara T, Iwai Y, Takahashi H, Hatakeyama D, Echigo N. Green tea catechins inhibit the endonuclease activity of influenza A virus RNA polymerase. PLoS Curr. 2009; 1:RRN1052. 
16. Shoji M, Takahashi E, Hatakeyama D, Iwai Y, Morita Y, Shirayama R, Echigo N, Kido H, Nakamura S, Mashino T, Okutani T, Kuzuhara T. Anti-influenza activity of $\mathrm{C}_{60}$ fullerene derivatives. PLoS One. 2013; 8:e66337.

17. Mantani N, Andoh T, Kawamata H, Terasawa K, Ochiai H. Inhibitory effect of Ephedrae herba, an oriental traditional medicine, on the growth of influenza A/PR/8 virus in MDCK cells. Antiviral Res. 1999; 44:193-200.

18. Nagai T, Kataoka E, Aoki Y, Hokari R, Kiyohara H, Yamada H. Alleviative effects of a Kampo (a Japanese herbal) medicine "maoto (ma-huang-tang)" on the early phase of influenza virus infection and its possible mode of action. Evid Based Complement Alternat Med. 2014, 2014:187036.

19. Baughman BM, Jake Slavish P, DuBois RM, Boyd
VA, White SW, Webb TR. Identification of influenza endonuclease inhibitors using a novel fluorescence polarization assay. ACS Chem Biol. 2012; 7:526-534.

20. Plotch SJ, Bouloy M, Ulmanen I, Krug RM. A unique cap (m7GpppXm)-dependent influenza virion endonuclease cleaves capped RNAs to generate the primers that initiate viral RNA transcription. Cell. 1981; 23:847-858

21. Nakamura Y, Oda K, Nakada S. Growth complementation of influenza virus temperature-sensitive mutants in mouse cells which express the RNA polymerase and nucleoprotein genes. J Biochem. 1991; 110:395-401.

(Received January 27, 2016; Revised February 16, 2016; Accepted February 17, 2016) 